\title{
Kidney Anastomotic Leak, CTCAE
}

National Cancer Institute

\section{Source}

National Cancer Institute. Kidney Anastomotic Leak, CT CAE. NCI Thesaurus. Code C143631.

A finding of leakage of urine due to breakdown of a kidney anastomosis (surgical connection of two separate anatomic structures). 